\title{
Technology of obtaining thermal insulation material on the basis of liquid glass by method of low temperature processing
}

\author{
Anna Zhigulina ${ }^{1, *}$, and Sergey Mizuriaev ${ }^{1}$ \\ ${ }^{1}$ Samara State Technical University, Institute of Architecture and Civil Engineering, 194, \\ Molodogvardeyskaya St., 443001, Samara, Russia.
}

\begin{abstract}
Absract. The paper deal with the development of energy saving technology for obtaining thermal insulation material on the basis of liquid glass. The aim of the research is to study processes of chemical and physical modification of soluble sodium silicate and change its rheology. The paper also considers development of technology for the production of thermal insulation material with porosity uniformly distributed throughout the volume and with the specified pores size. In this research the authors used both traditional methods (chemical analysis, physical-mechanical tests) and "thin" methods, i.e. differential thermal analysis, electron microscopy. For research in the field of rheology changes the authors developed a methodology for determination of viscoelastic properties of materials with variable rheology. For the development of resource-saving technologies the researchers used the method of laboratory simulation which is as close as possible to real production conditions. The research identifies regularities of processes of modification and swelling of liquidglass compositions and suggests methods for increasing viscosity of liquidglass compositions by introducing various modifying additives. It also introduces an energy-saving technology of porous granular material production, and proposes options for the production of effective thermal insulation material based on sodium silicate composition.
\end{abstract}

\section{Introduction}

Sodium silicate, and its aqua solution in particular, is widely used in a variety of industries. In Russia, an sodium silicate aqua solution is better known under its trade name "liquid glass" or "soluble glass." Liquid glass is obtained from sodium silicate (silicate blocks) and water during autoclave curing. Liquid glass is a transparent sticky liquid with a density of $1200-1500 \mathrm{~kg} / \mathrm{m}^{3}$, characterized by high adhesion properties.

It is widely known that liquid glass swells when heated to temperatures of about 150 $250{ }^{\circ} \mathrm{C}$ and increases 50-70 times in its volume formating high porous foam mass [1-2]. This property makes it possible to use liquid glass in the production of heat-insulating materials and products. The main advantages of these thermal insulation products, which distinguish them from traditional insulants are low density and low thermal conductivity.

\footnotetext{
*Corresponding author: auzhigulina@mail.ru
} 
Besides, they do not evolve toxic substances when being used or even burnt; are resistant to chemical and biological impacts, characterized by low water absorption (not more than $5 \%$ (thorough the volume) and, as a consequence, by durability (at least 100 years); by high strength (their compressive strength is not less than $0.7 \mathrm{MPa}$ ); and are easy to process.

That's why obtaining highly porous structures based on liquid glass by thermal processing holds much promise. This problem is studies by many research teams [3-16]. Research in this direction, both in Russia and abroad, is focused mainly on improving traditional technology of liquid glass and foam glass production. Various components are put into the raw mixture as additives, adjusting the specific properties of the product. These additives, being of natural or man-made origin, are local materials, typical for the region in which the specific raw material composition was developed. Analysis of existing technologies, literature and patent information suggests that the development of energysaving production technology of modified liquid glass production with the use widespread materials as additives is an actual scientific and technological challenge.

\section{Materials and Methods}

To achieve the aim of the research it was necessary to study processes which take place during thermal synthesis of sodium and sodium-based components and lead to the formation of sodium-silicate compounds. The authors analyzed state diagram of the system $\mathrm{Na}_{2} \mathrm{O}-\mathrm{SiO}_{2}$. This system served as the basis for the equilibrium system $\mathrm{SiO}_{2}-\mathrm{Na}_{2} \mathrm{O}-\mathrm{aq}$, widely used in insulation materials technology based liquid glass. According the theoretical data $[1,2]$ melting in a triple system $\mathrm{SiO}_{2}-\mathrm{Na}_{2} \mathrm{O}$-aq begins at temperatures above $48{ }^{\circ} \mathrm{C}$. This is due to the fact that the cation and anion $\mathrm{Na}_{2}$ and $\mathrm{SiO}_{3}$ bind only electrostatic interaction. They are able to make only weak hydrogen bonds with hydroxyl groups. It means that even at a temperature of $48{ }^{\mathrm{O}} \mathrm{C}$ crystal structure collapses and crystallohydrate melts in its own water.

The volume of hydrated water affects the melting temperature of alkaline silicate. If this silicate contains $20 \%$ of hydrated water, it melts at a temperature of $100{ }^{\circ} \mathrm{C}$. With rapid heating up to $200{ }^{\circ} \mathrm{S}$, hydrated silicate deliquates and hydrated water turns into steam. Due to the viscosity of liquated silicate, water vapors are trapped in it, forming bubbles with thin walls.

The research also explored swelling processes in liquid glass compositions. The study confirmed published data on the high degree of pore formation in liquid-glass masses during heat treatment and found that the increase of liquid glass density leads to an increase in its swelling ability. Experimental results showed that even from ordinary liquid glass with high density it is possible to obtain only porous pellets with arbitrary shape (not spherical), and without a crust (indicating a high water absorption and low strength). When ordinary liquid glass is heated, the obtained pellets stick together, forming an irregularly shaped material with arbitrary sizes.

Thus, it was proved that the basic technical and engineering difficulty of producing insulation materials on the basis of liquid glass lies in the fact that porosity which is formed when heated is very uneven (both in pores size and their distribution throughout the volume). For obtaining granular material with uniform porosity the most difficult thing was to obtain spherical micro-porous pellets with compacted outer crust (similar to ceramsite granulars) from sodium silicate composition. Therefore, in the course of further research we examined regularities of processes of modification and swelling of liquid-glass compositions. Tests showed that the form of obtained foamed pellets became more spherical with the simultaneous appearance of the crust when viscosity of liquid glass was increased. 
Experimental research of methods to increase the viscosity of sodium silicate composition showed that the most effective way was introducing the acids and salts of alkali metals. Interaction of liquid-glass compositions with solutions of alkali metal salts is a complicated physical-chemical process, the details of which are not yet clarified. It is assumed that chemical interaction between alkali metal salts and components of liquid glass able of forming new compounds is hardly possible. We believe that it is rather a process of silica gel coagulation by electrolytes of alkali metal salts present in solution $[1,16]$. According to the data, the process of coagulation of liquid glass during the introduction of different salts of acids is influenced by both cations and anions of these salts. The ability to cause a coagulation uniform throughout the volume that results in obtaining the mixture capable of being formed into raw pellets of specified size and later form spherical pellets after heat treatment is considered to be the main criterion in determining the effectiveness of additives. The following elements were tested as additives: hydrochloric acid and phosphoric acid, sodium chloride, calcium and ammonium, sodium nitrate, sodium and potassium sulphates, sodium hydroxide.

Table 1 shows the results of experiments of influence of liquid glass some chemical composites on its reology characteristics and type of thermal distensibility of liquid glass with additives 
Table 1. Additives influence of reology characteristics and distensibility of liquid glass

\begin{tabular}{|c|c|c|c|}
\hline \multirow{2}{*}{ Additive type } & \multirow{2}{*}{$\%$} & \multicolumn{2}{|r|}{ Results } \\
\hline & & $\begin{array}{l}\text { Raw mass } \\
\text { coagulation }\end{array}$ & $\begin{array}{l}\text { Formed pellets } \\
\text { distention }\end{array}$ \\
\hline 1 & 2 & $\mathbf{3}$ & 4 \\
\hline \multirow{2}{*}{$\begin{array}{l}\text { Hydrochloric } \\
\text { acid }\end{array}$} & 2 & Rapid coagulation & \multirow{2}{*}{ No distention } \\
\hline & 5 & Rapid coagulation & \\
\hline \multirow{2}{*}{$\begin{array}{l}\text { Orthophosphoric } \\
\text { acid }\end{array}$} & 2 & Rapid coagulation & \multirow{2}{*}{ No distention } \\
\hline & 5 & Rapid coagulation & \\
\hline \multirow{2}{*}{ Sodium chloride } & 5 & $\begin{array}{l}\text { Coagulation with } \\
\text { unformable mass }\end{array}$ & $\begin{array}{l}\text { Distention with pellets of } \\
\text { irregular form }\end{array}$ \\
\hline & $\begin{array}{l}1 \\
0\end{array}$ & $\begin{array}{l}\text { Coagulation with } \\
\text { formable mass }\end{array}$ & $\begin{array}{l}\text { Distention with pellets of } \\
\text { sphericity form }\end{array}$ \\
\hline \multirow[b]{2}{*}{ Calcium chloride } & $\begin{array}{l}1 \\
0\end{array}$ & White precipitation & \multirow[t]{2}{*}{ No distention } \\
\hline & $\begin{array}{l}5 \\
0\end{array}$ & $\begin{array}{l}\text { White precipitation, } \\
\text { progressive curing of } \\
\text { mass }\end{array}$ & \\
\hline \multirow[b]{2}{*}{ хлорид аммония } & 5 & & \multirow[t]{2}{*}{ No distention } \\
\hline & $\begin{array}{l}1 \\
0\end{array}$ & Rapid curing of mass & \\
\hline \multirow[b]{2}{*}{ Sodium nitrate } & $\begin{array}{l}1 \\
0\end{array}$ & White precipitation & \multirow[t]{2}{*}{ No distention } \\
\hline & $\begin{array}{l}5 \\
0\end{array}$ & $\begin{array}{l}\text { White precipitation, } \\
\text { progressive curing of } \\
\text { mass }\end{array}$ & \\
\hline \multirow{2}{*}{ Sodium sulfate } & $\begin{array}{l}1 \\
0\end{array}$ & White precipitation & \multirow[t]{2}{*}{ No distention } \\
\hline & $\begin{array}{l}5 \\
0\end{array}$ & $\begin{array}{l}\text { White precipitation, } \\
\text { mass surface crusting }\end{array}$ & \\
\hline
\end{tabular}

The experiments demonstrated that the most effective modifying additive was sodium chloride. The introduction of this substance resulted in gradual coagulation of liquid glass. Viscosity of the mass gradually increased and acquired plastic-elastic properties, which made possible to form pellets. Heat treatment of these pellets resulted in their considerable swelling, they squired spherical shape, then they solidified and preserved the acquired form. Foamed spherical pellets had homogeneous high-porous inner structure with external 
compacted crust. In addition, it was taken into account that among all tested substances sodium chloride was the most affordable and cheap material.

In the next phase of works the authors studied processes of swelling of liquid glass compositions which were modified with sodium chloride, and determined the impact of the type and quantity of the components on the swelling ability and formability of liquid glass compositions. These experiments demonstrated that the minimum density of pellets $(0.22$ $\mathrm{g} / \mathrm{cm}^{3}$ ) is achieved when using liquid glass of $1.51 \mathrm{~g} / \mathrm{cm}^{3}$ density (Fig. 1) and while adding modifying additives in the amount of 3-10\% of the mass of liquid glass (см. табл. 1).

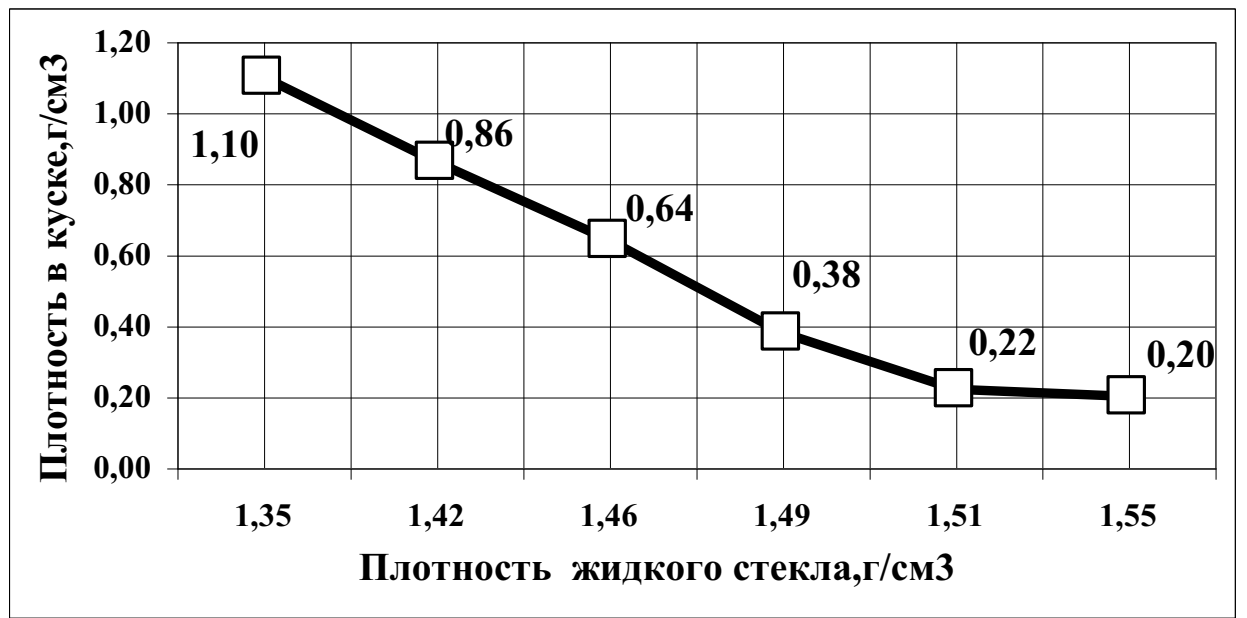

Fig.1. Influence of liquid glass density on pellet surface of aggregates

Further experiments allowed to define optimal swelling modes for the developed materials. The material of developed mixtures was pelletized and subjected to heat treatment at 250-300 ${ }^{\circ} \mathrm{C}$. Foamed pellets which were heated on the bottom of stationary kilns were of an irregular shape. Th improve the form of pellets the researchers used a rotating disk pelletizer, integrated in a laboratory kiln. After heat treatment at this installation the form of the pellets became close to spherical. The obtained pellets had a dense solid crust and internal high-porous structure. Then the researches applied an energysaving technology of low-temperature swelling at $300{ }^{\circ} \mathrm{C}$ for 10 minutes. In a kiln pelletizer spherical porous pellets with the following characteristics derived from physicomechanical tests were obtained: density in the piece $-0.22 \mathrm{~g} / \mathrm{cm}^{3}$; bulk density -150 $\mathrm{kg} / \mathrm{m}^{3}$; splitting strength $-0.07 \mathrm{MPa}$; water resistance factor -0.3 .

Thus, it was possible to create composite materials with specified properties on the basis of the developed highly porous material by introducing various additives. The authors received heat granulated material and granulates with increased strength, water resistance and biostability [17-19]. The characteristic feature of these granular materials was their low density and their constant "ceramsite" structure, i.e. the presence of external and internal shell of compacted high porous foam structure. Further results showed sufficient stability of these materials properties. Results of microscopic studies of materials samples showed the presence of nanoscale pores inside these materials [20]. It makes possible to consider the obtained material suitable for creating effective innovative insulating material on its basis.

\section{Results}


The researchers explored possibilities of modifying liquid glass in order to obtain granulated material with homogeneous porous structure. These experiments yielded the following results:

- Processes taking place during thermal synthesis of sodium-and sodium-based components and leading to the formation of sodium-silicate compounds were studied and described.

- The influence of different technological modes on the nature of liquid glass swelling masses was analized and the optimal mode was found.

- Regularities of processes of modifying liquid glass compositions modification were investigated and a unique component (sodium chloride) was pointed out. Sodium chloride has the ability to cause a coagulation uniform throughout the volume that results in obtaining the mixture capable of being formed into raw pellets of specified size and later form spherical pellets after heat treatment.

- The authors studied processes of swelling of liquid glass compositions which were modified with sodium chloride, and determined the impact of the type and quantity of the components on the swelling ability and formability of liquid glass compositions.

- Technology of obtaining granulated porous material on the basis of liquid glass by a method of low temperature processing was worked out.

- The possibility of introducing additives capable of obtaining material with specified properties into the developed composition was investigated.

\section{Discussion}

Research results show that liquid glass can be modified by introducing a certain amount of sodium chloride. As the result, we get uniformly coagulated viscous mass which can be formed in different ways. It allows to solve the problem of obtaining granulated material from liquid glass. At low temperature swelling of raw granules we obtain high-porous material of "ceramsite" structure with an external compacted shell and an internal highporous structure. This material is unique because it is possible to attach different properties to it by entering various components in the raw mixture composition.

\section{Conclusions}

The developed energy-efficient technology makes it possible to obtain granular highporous material on the basis of liquid glass by a method of low temperature processing. The obtained granulated high-porous material might be used as a basis for innovative insulating material which properties may be adjusted by the introduction of additives. It is possible to use widespread available materials, including the industrial wastes, as additives.

\section{References}

1. P.N. Grigorev, M.A. Matveev, Fluid glass (Promstrojizdat, Moscow, 1956)

2. V.I. Korneev, V.V. Danilov, Production and application of fluid glass (Stroiizdat, Leningrad, 1991)

3. Y.P. Karnaukhov, V.V. Sharov, Construction materials 11, 14-16 (1994)

4. A.I. Kudyakov, T.N. Radina, M.Yu. Ivanov, Building materials 11, 12-13 (2004)

5. Yu.G. Ivashchenko, A.A.Surnin, N.V. Zobkova, Liquid glass composition (Patent № 2158717 RU, MPK C 04 B 28/26 req. Saratov State Technical University 16/02/99; pub. 10.11.2000. Bul. № 31) 
6. V. A. Reshetov, V. T. Pavlov, A. T. Pavlov, Means to obtain porous material on the basis of liquid glass. (Patent № 2177922 RF, MPK C 04 B 28/26, C 04 B111:40 req. Rechetov Vyacheslav Aleksandrovich, Pavlov Vladimir Tikhonovich, Pavlov Anatoly Tikhonovich 24/08/00; pub. 10.01.02. Bul. № 1.)

7. A.I. Kudyakov, T.N. Radina, M.Yu. Ivanov, Raw materials mixture and method of obtaining foam silicate insulating material (Patent № 2267468 RU, MPK C 04 B 28/26 req. State educational institution of higher professional education "Bratsk State Technical University 30/03/04; pub. 20.02.2012. Bul. № 5.)

8. Yu.G. Ivashchenko, R.V Fomin, Liquid glass composition (№ 2245861 RF, MPK C 04 B 28/26. req. Saratov State Technical University 15/11/02; pub. 10.02.2005. Bul. № 4)

9. I.B.Bessonov, A.N.Salepin, N.P.Kordyukov, Method of obtaining constructioninsulation building material based on aluminosilicate microspheres (Patent № 2455253 RU. MPK C 04 B 28/26 req. Federal State budgetary institution "Scientific Research Institute of building physics. Russian Academy of architecture and building science 01/03/11; pub.: 10.07.2012. Bul. № 12)

10. Yu.G. Ivashchenko, R.V Fomin, Liquid glass composition (Patent № 223597 RF, MPK C 04 B 28/26 req. Saratov State Technical University 19/11/2002; pub. 10.09.2004. Bul. № 25)

11. A.B. Fashchevskiy, A.A.Fashchevskiy, M.A.Fashchevskiy, Method of producing a building material (Patent № 2333176 RU MPK C 04 B 28/26, C 04 B 111/20; req. A.B. Fashchevskiy, A.A.Fashchevskiy, M.A.Fashchevskiy 05/03/2007; pub. 10.09.2008. Bul. № 25)

12. A.P. Korsakov, A.A.Korsakov, P.A.Korsakov, Method of obtaining constructioninsulation foam glass (Patent 2451644 RF, MPK C 03 C 11/0000, C 03 B 19/08; req. KONAK INDUSTRY Inc. (CONAC INDUSTRY INC) (VG) 10/22/2010; pub. 5.27.2012, Bul. № 15)

13. V.Z. Leonidov, Production of foam glass (Patent 2455245 RU, MPK C 03 C 11/0000, C 03 B 19/08; req. Leonidov V.Z. 25/02/2011; pub. 10.07.2012, Bul. № 19)

14. V.A. Smoliy, E.A.Yatsenko, V.A. Guziy, Foamed slag glass (Patent 2448919 RU, MPK C 03 C 11/00 req. State educational institution of higher professional education "South-Russian State Technical University (Novocherkassk Polytechnical Institute. 09.09.2010; pub. 27.04.2012. Bul. № 12)

15. Yu.A. Shchepochkina, Production of glazed foam glass (Patent 2431619 RF, MPK C 03 C 11/00, C 03 B 19/08; req. Shchepochkina Yu.A. 15/03/2010; pub. 20.10.11, Bul. № 29)

16. Yu.A. Shchepochkina. Production of foam glass (variants) (Patent $2452701 \mathrm{RF}, \mathrm{MPK}$ C 03 C 11/00, C 03 B 19/08. Applicant and patentee:Shchepochkina Yu.A. №2010149109/03; req. Shchepochkina Yu.A. 30/11/2010; pub. 10.06.12, Bul. № 16)

17. O.l. Figovskiy, P.G. Kudryavtsev, Don Engineering bulletin 29, 117 (2014).

18. S.A. Mizuriaev, A.Yu. Zhigulina, A.N. Mamonov, N.V. Ivanova, Construction materials 7, 12-13 (2011)

19. S.A. Mizuriaev, A.Yu. Zhigulina. Urban planning 1, 82-84 (2012)

20. S.A. Mizuriaev, A.Yu. Zhigulina, G.S. Solopova, Procedia Engineering 111, 540-544 (2015)

21. A.M. Guryanov, S.A. Mizuriaev, V.M. Lebedev, V.T. Lebedev, Proceedings of the $V$ Eurasian scientific-practical Conference "Strength of non-homogeneous structures", $136(2010)$ 